\title{
Total occlusion of the abdominal aorta in a patient with renal failure and refractory hypertension: a case report
}

\section{Occlusione totale dell'aorta addominale in un paziente con insufficienza renale e ipertensione refrattaria. Descrizione di un caso}

\author{
Cinzia Perrino, Laura Scudiero, Maria Piera Petretta, Gabriele Giacomo Schiattarella, \\ Mario De Laurentis, Federica Ilardi, Fabio Magliulo, Giuseppe Carotenuto, Giovanni Esposito
}

\begin{abstract}
Total occlusion of the abdominal aorta in a patient with renal failure and refractory hypertension: a case report. C. Perrino, L. Scudiero, M.P. Petretta, G.G. Schiattarella, M. De Laurentis, F. Ilardi, F. Magliulo, G. Carotenuto, G. Esposito.

Total occlusion of the abdominal aorta is unusual, and potentially catastrophic. It occurs in patients with advanced atherosclerotic occlusive disease, and can cause severe ischemic manifestations, depending on the site of obstruction. Prompt and appropriate diagnostic and therapeutic approaches are important whenever this condition is suspected, in order to avoid a fatal outcome. The development of a complex network of collaterals may prevent the manifestation of acute ischemic phenomena, and cause a delay in diagnosis and treatment. Here we report the clinical case of
\end{abstract}

a 59-year-old man who was referred to our Department for evaluation of renal failure and refractory hypertension. UItrasonography and 99mTc-DTPA scintigraphy showed a shrunken, non-functioning left kidney, while CT angiography and aortography showed the complete occlusion of the aorta from below the right renal artery down to the bifurcation of both common iliac arteries, with a critical stenosis of the origin of the right renal artery, an occlusion of the left renal artery as well as of the origin of the inferior mesenteric artery. The patient was referred to the surgery department for aorto-bifemoral bypass surgery and re-implantation of the right renal artery.

Keywords: atherosclerosis, abdominal aorta.

Monaldi Arch Chest Dis 2011; 76: 43-46.

Division of Cardiology - Federico II University of Naples, Italy.

Corresponding author: Giovanni Esposito MD, PhD; Division of Cardiology; Federico II University; Via Pansini 5; I-80131 Naples; Italy; Tel: +390817462216; Fax:+390817462223; E-mail address: espogiov@unina.it

\section{Introduction}

Total occlusion of the abdominal aorta is an uncommon, but potentially dangerous manifestation, which requires early recognition and intervention [1]. It is due to the proximal propagation of an occlusive distal aortic thrombus in patients with advanced atherosclerotic occlusive disease, and can cause severe ischemic manifestations in the lower extremities, spinal cord, intestine and kidneys, depending on the site of obstruction [2]. Despite its severity, atherosclerotic occlusion of the abdominal aorta is an easily missed diagnosis, since the development of extensive collateral vasculature [3] can maintain for a long time adequate basal perfusion of the intestines and of lower extremities, and prevent manifestation of the acute ischemic events. Here we describe the clinical case of a 59-year-old man with renal insufficiency and refractory arterial hypertension, and presenting severe aorto-iliac atherosclerotic occlusive disease.

\section{Case presentation}

A 59-year-old man was referred to the nephrology department of our University Hospital for eval- uation of imparaired renal function and uncontrolled arterial hypertension that was refractory to medical management. His medical history included chronic renal disease stage III (first diagnosis nine months earlier), hypertension (first diagnosis three years earlier), bilateral leg intermittent claudication. Cardiovascular risk factors included remote history of cigarette smoking, hyperlipidemia, and a family history of atherosclerosis. On admission, a harsh systolic murmur was heard over the aortic valve, the carotids and the femoral arteries. A murmur was also heard over the abdominal aorta, but only at the supra-umbilical level, with abrupt interruption of the murmur below the umbilicus. The pulses were normal over the radial arteries and palpable but less strong over both femoral arteries. The pulses over dorsalis pedis arteries were barely palpable. Systolic blood pressure (measured with Doppler ultrasound) was $180 \mathrm{mmHg}$ over the brachial arteries in both arms, and $80 \mathrm{mmHg}$ over the dorsalis pedis arteries in both legs. Laboratory studies included: $\mathrm{Hct}=35 \%, \mathrm{Hb}=11 \mathrm{~g} / \mathrm{dl}, \mathrm{WBC}=$ $5300 / \mu \mathrm{l}, \mathrm{PLT}=173000 / \mu \mathrm{l}, \mathrm{PT}=12.4 \mathrm{~s}, \mathrm{PTT}=32.9$ $\mathrm{s}, \mathrm{FG}=284.62 \mathrm{mg} / \mathrm{dl}$, serum urea $=130 \mathrm{mg} / \mathrm{dl}, \mathrm{SCr}$ $=2.3 \mathrm{mg} / \mathrm{dl}, \mathrm{eGFR}=24 \mathrm{ml} / \mathrm{min} / 1.7 \mathrm{~m}^{2}$. Tests for a 
hypercoagulable state and cancer indices were negative. Intensive work-up failed to reveal any underlying cancer or systemic disease. Ultrasonography showed a right kidney measuring $10 \times 5 \mathrm{~cm}$ and a shrunken left kidney. A 99mTc-DTPA scintigraphy demonstrated a well-functioning right kidney and a non-functioning left kidney. A CT angiography revealed the absence of radiocontrast media in the aorta from below the right renal artery down to the bifurcation of both common iliac arteries, due to thrombosis. The patient was brought to our department to undergo aortography that was performed with right femoral access and left radial access using the Seldinger technique. The aortography showed the complete occlusion of the aorta from below the right renal artery down to the bifurcation of both common iliac arteries, with a critical steno-
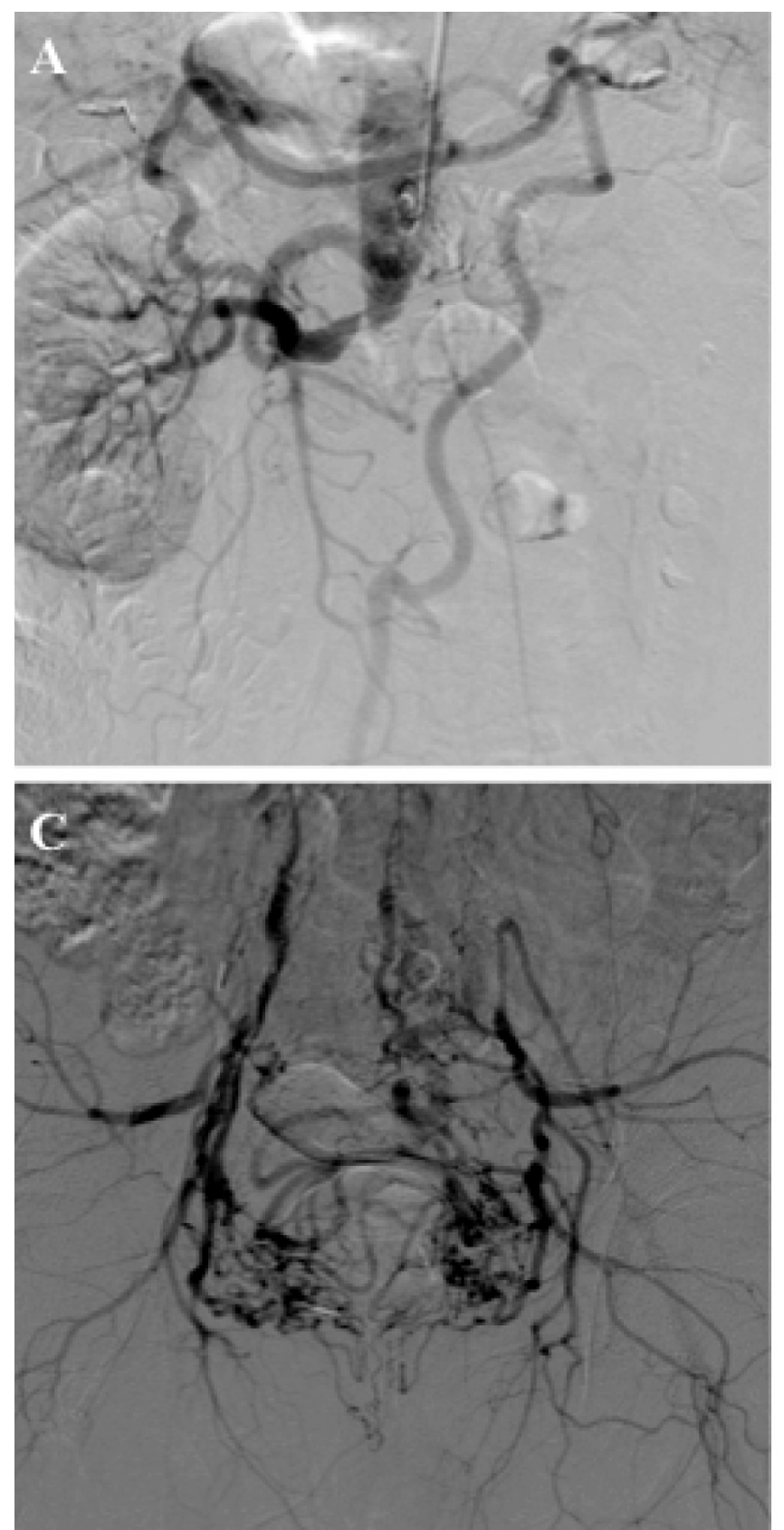

sis of the origin of the right renal artery, an occlusion of the left renal artery as well as of the origin of the inferior mesenteric artery, that was reconstituted via the Riolan's arch (Figure 1A). The iliac vessels were reconstituted via collaterals derived from the inferior mesenteric artery (Figure 1B, C, D). Based on the angiographic results, the diagnosis of chronic ischemic nephropathy and renovascular hypertension was made. In order to reduce the ischemic damage of the right kidney, and to avoid the recourse to a dialysis therapy, it was proposed to the patient to undergo a percutaneous treatment of the right renal artery stenosis. However, the excessive thrombus extension didn't allow such treatment, and the patient was referred to the surgery department to perform aorto-bifemoral bypass surgery and re-implantation of the renal artery.
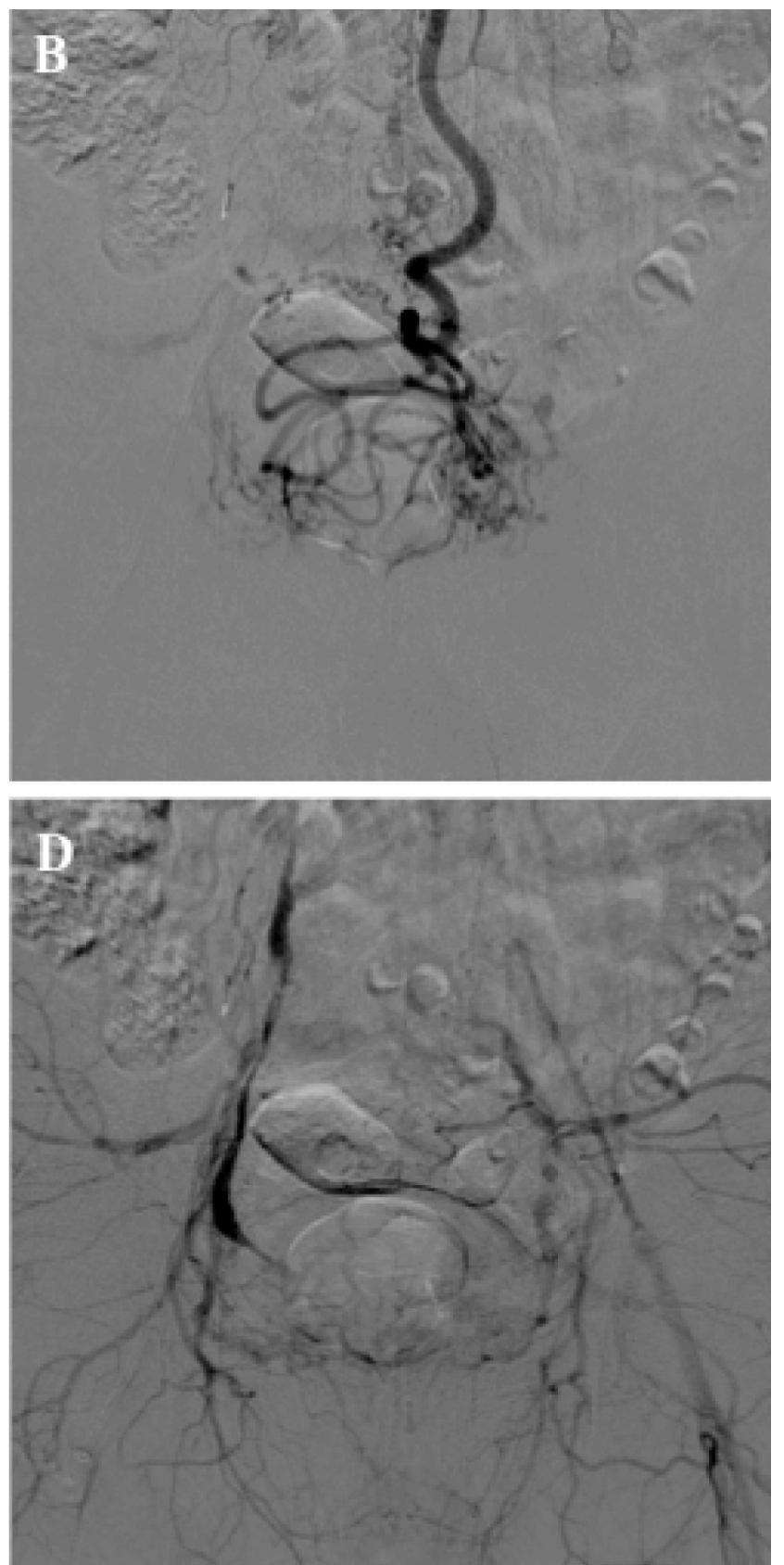

Figure 1. (A) Aortography showing the complete occlusion of the aorta from below the right renal artery down to the bifurcation of both common iliac arteries, with a critical stenosis of the origin of the right renal artery, an occlusion of the left renal artery as well as of the origin of the inferior mesenteric artery, that was reconstituted via the Riolan's arch. Aortography in the early $(\mathbf{B})$, mid $(\mathbf{C})$ and late $(\mathbf{D})$ phases showing the reconstitution at both iliac vessels via a complex network of collaterals. The internal iliac arteries were reconstituted via collaterals derived from the inferior mesenteric artery (superior rectal artery), while the external iliac arteries were reconstituted via collaterals derived from internal iliac arteries and via the inferior epigastric arteries. 


\section{Discussion}

Complete aortic occlusion is an uncommon, but potentially dangerous clinical condition. The clinical presentation may vary from limb ischemia, neurologic symptoms of the lower extremities, abdominal symptoms and refractory hypertension [2]. This clinical picture is caused by embolic occlusion or, more often, by superimposed thrombosis of an atherosclerotic abdominal aorta. Pre-existing atherosclerosis combined with a low-flow state, due to reduced cardiac performance or severe volume depletion, is a relatively frequent cause of acute aortic occlusion [2]. Some cases are due to hypercoagulable states and cause thrombosis of aneurysm of the abdominal aorta [4]. Aortic occlusion usually occurs in the infrarenal abdominal aorta, often at or near the bifurcation, while occlusion of the suprarenal aorta is much less common [5]. In a study by Tapper $e t a l$, approximately $12 \%$ of the cases of occlusion of the abdominal aorta were located in the suprarenal region. More than two-thirds of this group had chronic atherosclerotic disease of the infrarenal aorta, with proximal propagation of thrombus to involve the suprarenal aorta [6]. The main manifestations in these patients were a history of lower limb claudication, reduced renal function, decreased or absent femoral pulses and refractory hypertension [1-5-6]. Hypertension, hyperlipidemia, a family history of atherosclerosis and a strong history of tobacco abuse are the major risk factors [5]. Although early diagnosis of aorto-iliac disease is important in order to avoid a fatal outcome, atherosclerotic occlusion of the abdominal aorta is an easily missed diagnosis. Indeed, symptoms alone can be misleading, due to the development of extensive collateral vasculature, which can maintain for a long time adequate basal perfusion of the intestines and of lower extremities, and prevent the manifestation of acute ischemic events [3]. In case of complete occlusion of the distal aorta in which the orifice of the inferior mesenteric artery is also involved, the direction of blood flow is from the superior mesenteric artery to the inferior mesenteric artery via the Riolan's arch. The inferior mesenteric artery also participates as a collateral channel in occlusive disease of the iliac arteries. The anastomosis between the superior rectal artery (distal branch of the inferior mesenteric artery) and the branches of the internal iliac (middle and inferior rectal branches) and external iliac arteries are enlarged, and these connections are capable of providing the blood supply of the lower extremities [7-8-9]. A simple, readily-available and noninvasive method for the early diagnosis of aortic occlusion is duplex scanning and ultrasonography, with a sensitivity of $91 \%$ and specificity of $93 \%$ [10]. However, angiography plays a vital role to assess the anatomy and extensions of aortic lesions, and to customize the optimal management in each patient. Indeed, aortography demonstrates the extension of thrombus to the renal arteries, the status of the distal circulation, and also delineates the status of the visceral circulation [2].

Surgery is the treatment of choice for patients with diffuse disease involving the aorta and both iliac arteries [11]. Two surgical modalities are avail- able for the management of suprarenal aortic occlusions. For patients with a short life expectancy, with near normal renal functions and controlled blood pressure, axillo-bifemoral bypass is the treatment of choice [12]. Other patients will require aortic reconstruction and thrombectomy of the juxtrarenal segment [12-13]. The operative mortality in chronic infrarenal aortic occlusion is approximately 5\% [14], while in chronic suprarenal aortic occlusion is nearly $23 \%$ [6].

The endovascular treatment is a valid alternative to conventional surgical therapy for isolated atherosclerotic lesions of the infrarenal aorta [15-16], and in some patients aortic stents can be implanted [17]. In these cases, the main cause of failure is the progression of the aorto-iliac disease. For properly selected patients, especially if young, aortic angioplasty with or without stent placement should be considered as first-line treatment for isolated segmental midaortic atherosclerotic stenosis [16]. In addition to the well-known advantages of endovascular treatment over conventional surgery (limited exposure, low operative morbidity-mortality, reduced cost, and short hospitalization), aortic angioplasty provides long-term results comparable to those of open repair, and limits the risk of secondary erectile dysfunction or bowel dysfunction [16].

The history, clinical findings and the extended collateral circulation in our patient suggested a chronic, severe aorto-iliac atherosclerotic occlusive disease; the smaller size of the left kidney, instead, was indicative of ischemic nephropathy. The manifestation of severe arterial hypertension and diminished renal function suggested a proximal propagation of the aortic thrombus. The extended collateral vascular network had protected the patient from acute ischemic manifestations for a long time, and was probably responsible for the late recourse of the patient to medical treatments. If the patient had been worked-up at the time of the first diagnosis of hypertension or renal failure, he could have undergone a timely and relatively safer endovascular approach or thrombectomy.

In conclusion, proximal propagation of an occlusive distal aortic thrombus to the suprarenal level, causing ischemic nephropathy, should be suspected in patients with refractory arterial hypertension, reduced renal function, absent or markedly decreased femoral pulses and a history of lower limb claudication, when risk factors (smoking, hyperlipidemia, a family history of atherosclerosis) are also evident. A prompt diagnostic approach is important whenever this condition is suspected.

\section{Riassunto}

L'occlusione totale dell' aorta addominale è un evento clinico raro ma catastrofico. Si verifica in soggetti con avanzata malattia aterosclerotica, $e$ può causare gravi manifestazioni ischemiche a carico di diversi organi e apparati secondo la sede di ostruzione. Quando si sospetta tale condizione, è importante un rapido e appropriato intervento diagnostico e terapeutico. Tuttavia, l' esteso circolo collaterale che può svilupparsi in tali condizioni può prevenire il manifestarsi di eventi ischemici acuti, 
ritardando la diagnosi e la terapia di questi pazienti. Descriviamo il caso clinico di un uomo di 59 anni giunto alla nostra osservazione per la recente comparsa di insufficienza renale e ipertensione arteriosa refrattaria alla terapia medica. L'ecografia dell'addome e la scintigrafia renale con $99 \mathrm{mTc}$ DTPA rivelavano un rene sinistro grinzo, non funzionante. Per tale ragione veniva eseguito l'angiografia aortica e dei vasi dei visceri addominali mediante angioTC e aortografia che dimostravano estesa trombosi dell'aorta addominale con occlusione del vaso subito a valle dell'arteria renale destra che presentava stenosi subocclusiva all' origine, occlusione dell'arteria renale sinistra e del tratto prossimale dell'arteria mesenterica inferiore. Per tale quadro clinico, il paziente veniva trasferito nel reparto di Chirurgia per eseguire bypass aorto-bifemorale e re-impianto dell' arteria renale destra.

Parole chiave: aterosclerosi, aorta addominale.

\section{ABBREVIATIONS LIST:}

99mTc-DTPA: Technetium-99m labelled diethylenetriamine penta-acetate;

CT: Computed Tomography;

Ht: hematocrit;

$\mathrm{Hb}$ : hemoglobin;

WBC: white blood cells;

PLT: platelets:

PT: prothrombin time;

PTT: partial thromboplastin time;

FG: fibrinogen;

SCr: serum creatinine;

eGFR: estimated glomerular filtration rate.

\section{References}

1. Sequeira JC, Beckmann CF, Levin DC. Suprarenal aortic occlusion. Am J Roentgenol 1978; 132: 773-776.

2. Babu SC, Shah PM, Nitahara J. Acute aortic occlusion: factors that influence outcome. J Vasc Surg 1995; 21: 567-572.

3. Sukharev II, Guch AA, Novosad EM, Vlaikov GG. Collateral compensation of blood flow and hemodynamics of the lower extremities in atherosclerotic occlusion of abdominal aorta. Klin Khir 2001; 12: 14-16.
4. Dossa CD, Shepard AD, Reddy DJ, et al. Acute aortic occlusion. A 40-year experience. Arch Surg 1994; 129: 603-608.

5. Hackam DG, Thain LMF, Abassakoor A, McKenzie FN, Spence JD. Trapped renal arteries: Functional renal artery stenosis due to occlusion of the aorta in the arch and below the kidney. Can J Cardiol 2001; 17: 587-592.

6. Tapper SS, Edwards WH, Edwards WH Jr, Mulherin JL Jr, Martin RS 3rd. Suprarenal aortic occlusion. J Vasc Surg 1993; 18: 372-380.

7. Moskowitz M, Zimmerman H, Felson B. The meandering mesenteric artery of the colon. Am J Roentgenol 1964; 92: 1088-1099.

8. Kornblith PL, Boley SJ, Whitehouse BS. Anatomy of the splanchnic circulation. Surg Clin North Am 1992; 72: 1-30.

9. Erden A, Yurdakul M, Cumhur T. Doppler waveforms of the normal and collateralized inferior mesenteric artery. Am J Roentgenol 1998; 171: 619-627.

10. Langsfeld M, Nepute J, Hershey FB, et al. The use of deep duplexscanning to predict hemodynamically significant aortoiliac stenoses. J Vasc Surg 1988; 7: 395-399.

11. Norgren L, Hiatt WR, Dormandy JA, et al. Inter-Society Consensus for the Management of Peripheral Arterial Disease (TASC II). Eur J Vasc Endovasc Surg 2007; 33 (Suppl 1): S1-75.

12. Liddicoat JE, Bekassy SM, Dang MH, De Bakey ME. Complete occlusion of the infrarenal abdominal aorta: management and results in 64 patients. Surgery 1975; 77: 467-472.

13. Gupta SK, Veith FJ. Management of juxtarenal aortic occlusions: technique for suprarenal clamp replacement. Ann Vasc Surg 1992; 6: 306-312.

14. Ligush J Jr, Criado E, Burnham SJ, Johnson G Jr, Keagy BA. Management and outcome of chronic atherosclerotic infrarenal aortic occlusion. J Vasc Surg 1996; 24: 394-405.

15. de Vries JP, van Den Heuvel DA, Vos JA, van Den Berg JC, Moll FI. Freedom from secondary interventions to treat stenotic disease after percutaneous transluminal angioplasty of infrarenal aorta: long-term results. $J$ Vasc Surg 2004; 39: 427-431.

16. Feugier P, Toursarkissian B, Chevalier JM, Favre JP. Endovascular treatment of isolated atherosclerotic stenosis of the infrarenal abdominal aorta: long term outcome. Ann Vasc Surg 2003; 17: 375-385.

17. Long AL, Gaux JC, Raynaud AC, et al. Infrarenal aortic stents: initial clinical experience and angiographic follow-up. Cardiovasc Intervent Radiol 1993; 16: 203-208. 